\title{
Analogical Model of the Deformation of Sandy Submarine Channels in Shaly Pelagic Sediments
}

\author{
M. Panien ${ }^{1 *}$, I. Moretti ${ }^{1}$ and S. Calassou ${ }^{2}$ \\ 1 Division Géologie-Géochimie, Institut français du pétrole, 1 et 4, avenue de Bois-Préau, 92852 Rueil-Malmaison Cedex - France \\ 2 TFE, CSTJF, avenue Larribau, 64018 Pau - France \\ e-mail: isabelle.moretti@ifp.fr \\ * now at University of Bern, marion.panien@geo.unibe.ch
}

\begin{abstract}
Résumé - Modélisation analogique de la déformation des chenaux sableux piégés dans des sédiments pélagiques argileux - Les marges grasses sont affectées par une forte déformation interne due à l'accroissement de la charge sédimentaire, à l'éventuel pendage régional et aux mouvements gravitaires qui en résultent. Ces mouvements affectent l'ensemble de la pile sédimentaire, y compris les chenaux sableux piégés dans la pile souvent argileuse ou silteuse. Du fait de ces mouvements, la géométrie des chenaux change et des failles apparaissent, qui peuvent affecter la qualité des réservoirs pétroliers que constituent ces chenaux. Dans ce travail, la déformation cassante des chenaux est approchée via des modèles analogiques. Le chenal est piégé dans une série ductile où un étalement gravitaire entraîne une extension multidirectionnelle. Les résultats montrent que le chenal est progressivement déformé et découpé par des failles. Celles-ci sont systématiquement perpendiculaires aux bordures des chenaux, n'affectent quasiment pas les méandres et sont peu dépendantes de la pente régionale.
\end{abstract}

Mots-clés : modèle analogique, chenaux, boudinage, système deltaïque.

\begin{abstract}
Analogical Model of the Deformation of Sandy Submarine Channels in Shaly Pelagic Sediments - The "grasse" margins are affected by strong deformation due to the increase of the sedimentary cover, the eventual basement tilt and the resulting gravity gliding. These movements affect the entire sedimentary sequence including the sandy channels often present in the shaly or silty pile. As a result, the channel shape changes with time, faults may appear that will break the sand continuity and therefore affect the petroleum reservoir quality of these channels. In this paper we document the brittle deformation of a channel through analogical models. The channel is embedded in ductile series where gravity sliding induces multi-directional extension. Results show that the channel is progressively deformed and cut by faults. These ones are systematically perpendicular to the channel borders, do not affect the meanders and are poorly dependent on the regional dip.
\end{abstract}

Keywords: analogical modelling, channels, boudinage, deltaic systems. 


\section{INTRODUCTION}

On some passive continental margins, a dense network of channels spreads across deltas. On the southeast Atlantic margin, offshore Congo and Angola, these channels are embedded in a very thick shaly sequence, which corresponds to the Zaire and Congo river delta.

A channel is an elongated groove and, generally, it corresponds to a current that eroded deposits forming sediments. Localised in deltas, these turbiditic channels are filled by sandy deposits which laterally pass to argillaceous levees on both sides. When they are sealed in argillaceous pelagic deposits, these channels can constitute excellent potential reservoirs for hydrocarbon accumulations. Such channels have already been described now in several places such as the Orinoco delta [1] or the African margin [2, 3]. They constitute the reservoir of recently discovered giant fields as Girasol (Angola, TotalFinaElf).

The geometry of these channels is still debated. In the studied cases, the location seems more influenced by the fault network of the sea floor than by the flow energy or other sediment-internal causes. Apparently, the channel is laterally migrating through time (Fig. 1). Onshore, river channels migrate since they erode the channel borders but on deep offshore sedimentary processes are different. In addition,

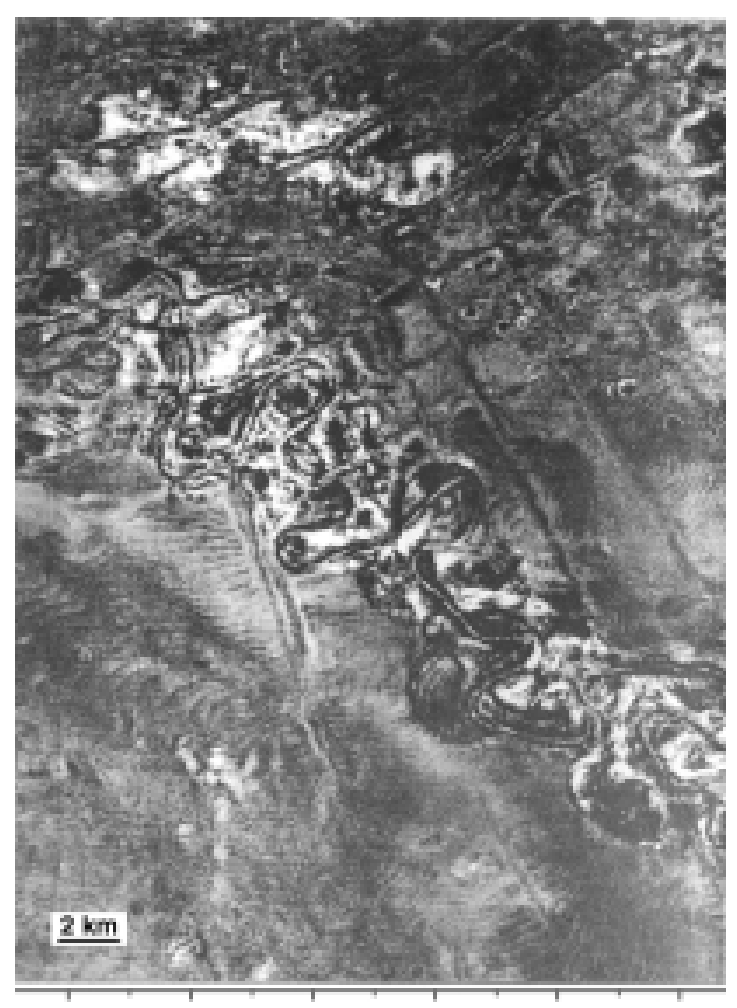

Figure 1

This map comes from high-resolution 3D seismic data set. It shows a normal fault network, orthogonally interrelated, and a highly sinuous turbiditic channel, about $250 \mathrm{~m}$ wide. the apparent figures of migration, seen on high-resolution 3D seismic lines, sometimes indicate a reverse displacement compared to the one expected in a meandering channel. The purpose of this paper is to propose a process to explain this channel geometry taking into account its post-deposition deformation.

\section{GRAVITY SPREADING}

Passive margins, and more particularly deltaic systems, are affected by gravity spreading: sediments are deformed under their own weight. The gravity instability is due to new sediment influx but also to an eventual tilt of the basement due to post-rift uplift of the continent margins. The deformation is usually made easier by the presence of decollement levels, such as salt and shale, which allow the propagation of the displacement over very large distances. Regional-scale seismic sections in Africa and in the Gulf of Mexico show a domain of extensional faulting near the continental margin, and a compressive faulting downslope at the extremity of the salt layer proving the transfer of the displacement over hundreds of kilometres [4]. Similarly, in the Tertiary shaly beds in the southeast Atlantic margin, the deformation occurs over a large distance and the shale flows from the continent to the ocean over very large distances. The flow of the incompetent layer is difficult to quantify since there is no marker, at the seismic scale, to record the deformation. Nevertheless, when brittle bodies, such as the sandy channels, are trapped in the shale, they could be a marker of this extension and indeed, buckling (boudinage) or small-scale tilted blocks are common (Fig. 2).

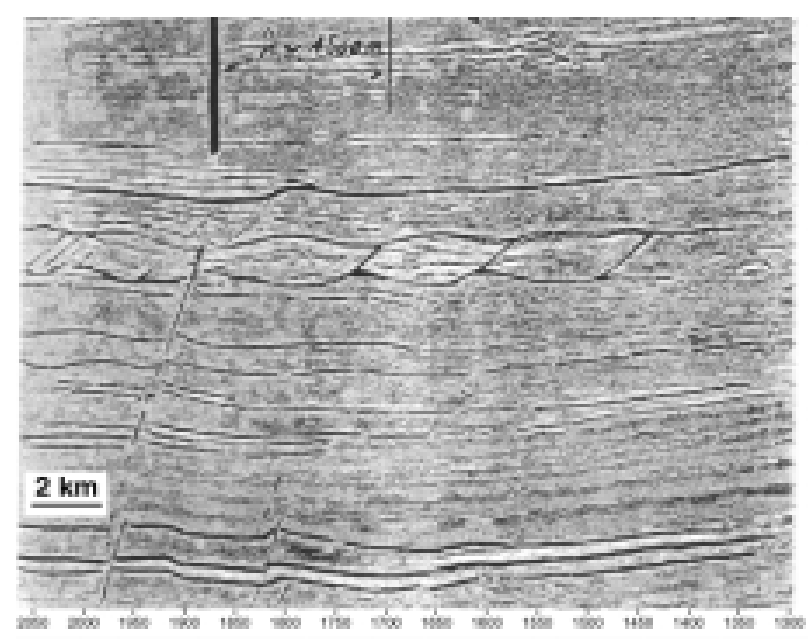

Figure 2

Boudins on a seismic line. A sandy channel is confined in a ductile matrix. Here, extension is accommodated by normal faulting in the matrix and also in the channel that develops boudinage structures. The boudin wavelength is of about $1.5 \mathrm{~km}$. 
We consider these features to be the mark of the gravity spreading which also affects the channels. During their development, their shape will thus progressively change. In order to test this model, we carried out analogical experiments showing the deformation of a brittle body trapped in a ductile body which has undergone the effect of gravity sliding.

\section{EXPERIMENTAL CONDITIONS}

Analogical modelling is carried out with sand and silicone putty. Models are mainly used to understand mechanisms of deformation. The advantage of these experiments is that we can test several assumptions to determine the genetic relation between boundary conditions and resulting structures because of the short duration of the experiment.

\subsection{Analogical Materials}

The two analogical materials used to simulate respectively the sandy channel and the shaly deposits were dry quartz sand and silicone putty.

We used sand with a grain size of about $100 \mu \mathrm{m}$. Dry sand has Mohr-Coulomb properties: the cohesion is very low and the coefficient of internal friction is similar in dry sand and in brittle rock (about $30^{\circ}$ ). Therefore, sand is used to simulate rocks with a brittle behaviour such as sandstone.

We used silicone putty (polydimethyl-siloxane, PDMS, Dow Corning SGM36), a viscous Newtonian material, to simulate the ductile behaviour of materials such as salt or argillaceous rocks.

An overview of the properties of these materials may be found in $[5,6]$.

\subsection{Building the Models}

The models are composed of one ductile layer incised by a sandy channel. The ductile layer is a silicone putty spread at the bottom of a sandbox, on a thin layer of vaseline (vaseline reduced basal friction conditions).

The models were built horizontally in a square wooden box and then tilted for $2^{\circ}$ (Figs. $3 a$ and $3 b$ ).

A rigid mould, sunk into the silicone putty, represents the channel shape. This mould allows us to reproduce the same shape of the channel for each experiment.

Then, the hollow made by the mould is filled with coloured sand.

Deformation is described in terms of the change in shape and size of a grid applied on the silicone putty. This grid is made up of squares ( $2 \mathrm{~cm}$ side), and each square contains a circle (with radius of $1.5 \mathrm{~cm}$ ). These circles become ellipses. An ellipse formed in this way is called a strain ellipse, and its orientation and dimensions characterise the deformation of the plane in which it lies (deformation in two dimensions).

\subsection{The Three Analogical Experiments}

\subsubsection{Model 1: Mono-Directional}

This model is composed of one rectangular layer $(16 \times 20$ $\times 2 \mathrm{~cm}$ ) of silicone putty at the bottom. This layer, incised by a sandy channel, is spread by gravity in a corridor of constant width. The flow is thus mono-directional and in the dip direction.

\subsubsection{Model 2: Multi-Directional Extension, Channel at the Top}

In this case, gravitational gliding is not guided by a corridor. The layer of silicone putty spreads over $180^{\circ}$. The flow is multi-directional and the channel is located at the surface.
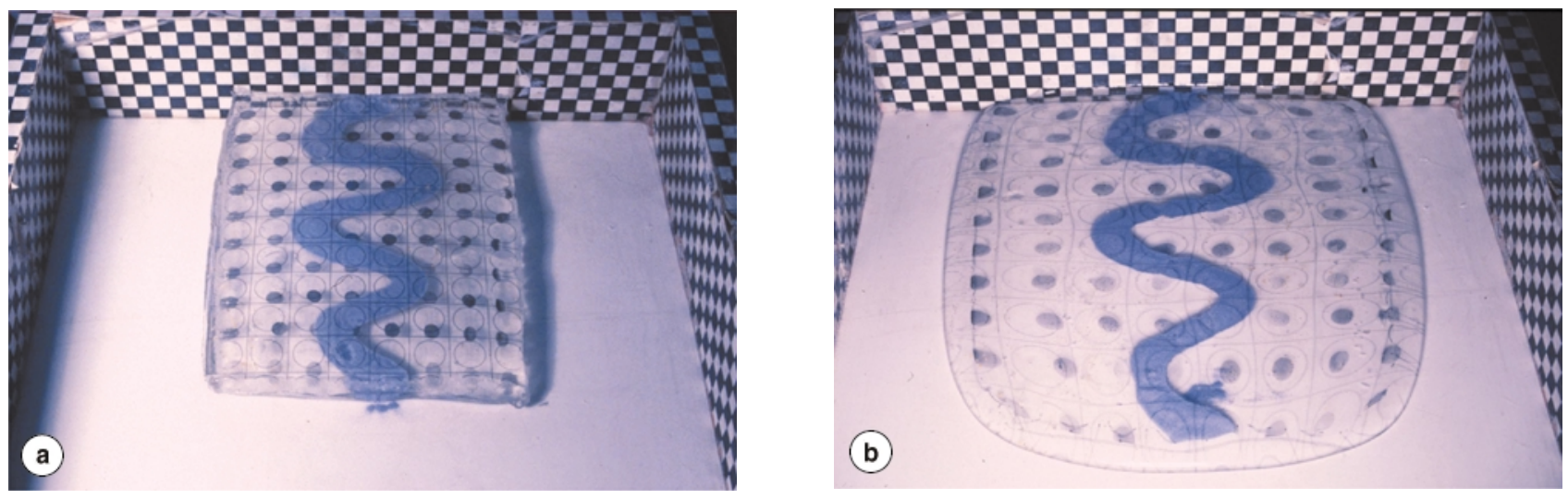

Figure 3

View of the experiment in initial and final stages. The model spreads in a square wooden box, on a tilted rigid basement.

(a) Initial stage: silicone putty incised by a blue sandy channel, the grid is orthogonal on the silicone putty; (b) Final stage: the shape of the grid shows the silicone deformation. 


\subsubsection{Model 3: Multi-Directional Extension, Channel Inside the Ductile Layer}

It is composed of two layers of silicone putty, $1 \mathrm{~cm}$ thick each. The sandy channel incises the basal layer and is confined between these two layers. Different grids are applied on each layer of silicone putty.

\section{DEFORMATION}

\subsection{First Observations}

During the experiment, the layer of silicone putty flows down the gentle slope under its own weight for about ten hours. Normal faults progressively appear in the sand that is brittle to accommodate this flow in the silicone. When deformation increases, the sandy channel becomes a rosary of isolated sand bodies.

The grids applied on the silicone putty allow us to follow easily the evolution of the deformation, even in the silicone. It can be seen that the channel influences the silicone deformation in all the models, especially when the channel is buried (Figs. $4 a, 4 b$ and $4 c$ ).

In Figures $3 \mathrm{a}$ and $3 \mathrm{~b}$ a frontal coiling of the silicone putty may be noted as well as strong rim effects. Both are artefacts due to boundary conditions, the vaseline used as a lubricant is not efficient enough to avoid it. The borders of the silicone have not been analysed to take this problem into account.

During the experiments, models have been regularly photographed. By superimposing photos of the same model, it is possible to follow the deformation of the circles and the appearance of faults throughout time. a Model 1
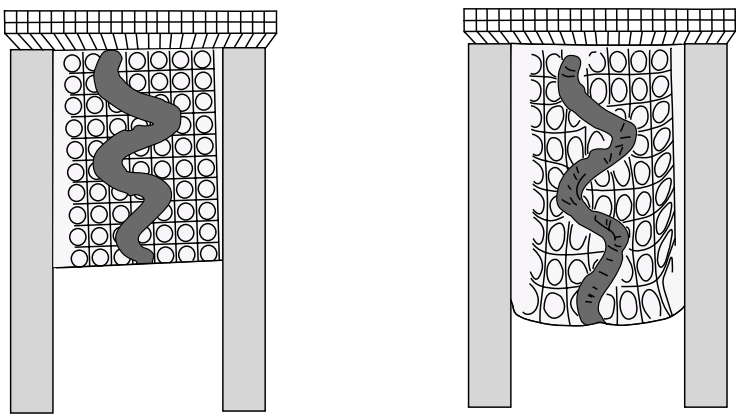

b Model 2
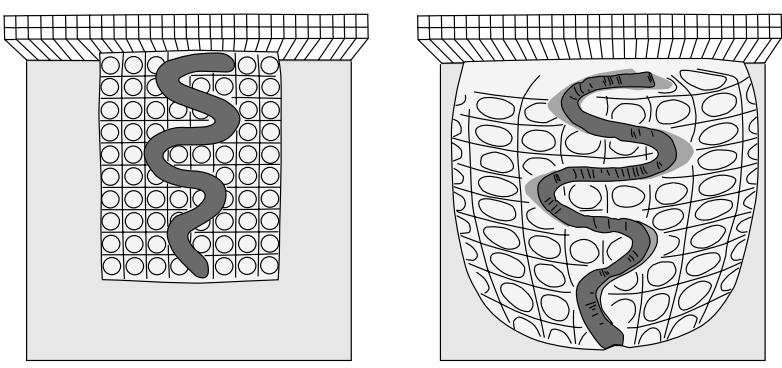

c Model 3
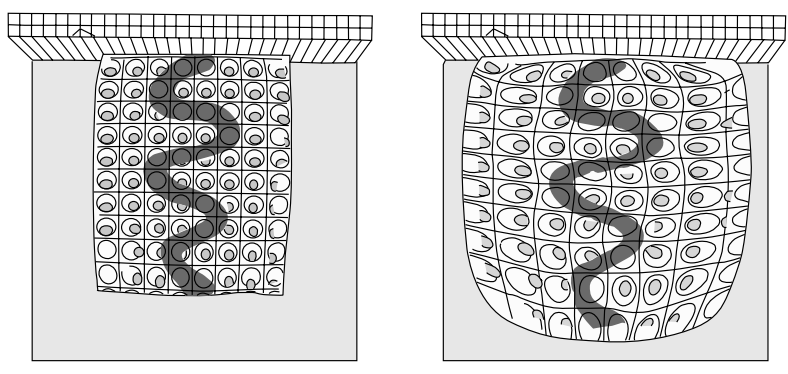

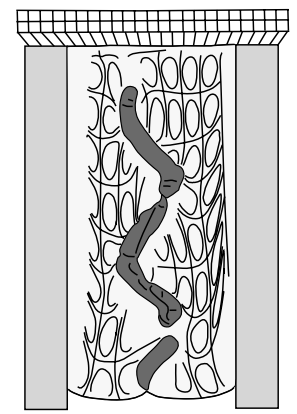

\section{Figure 4}

Upper surfaces of models at different successive stages of the experiment.

(a) Three stages: initial, intermediate and final. The spreading is monodirectional so the flow paths are parallel straight lines, trending downslope.

(b) and (c) Two stages: initial and final. The spreading is multi-directional. Paths are close to the radius of a half circle. 
The lengths of the semi-major and semi-minor axes of the ellipses are greater than the length of the initial circle radius. This highlights the fact that the extension is in all horizontal directions due to radial divergent gliding of the silicone putty in Models 2 and 3.

\subsection{Spreading Paths (Figs. $5 a$ and $5 b$ )}

\subsubsection{Model 1}

The particle paths are parallel to the dip and become divergent at the front of the model.

\subsubsection{Model 2}

The spreading paths are parallel to the dip in the middle of the model, divergent at the front and intermediate between the dip and the direction of the fixed edge of the model in the other part.

Paths become parallel to the dip near the front of the model.

\subsubsection{Model 3}

The spreading paths are parallel to the dip in the middle of the model, divergent at the front and perpendicular to the dip in the upper part of the model. Here, extension is purely lateral.

\subsection{Development of the Fault Network}

\subsubsection{Model 1: Mono-Directional Extension, Channel at the Top}

In this experiment, the channel is mainly unfolded in the dip direction but its length also increases. Faults are mainly localised at the front of the model, that is the distal part of the margin, since the silicone flow rate is maximal near the free border. The length increase of the channel between the last two meanders reaches $20 \%$ in $4 \mathrm{~h}$, whereas is almost 0 in the first two meanders near the fixed border. The faults, produced by the extension in the sand, are perpendicular to the border of the channel, which also rapidly becomes the main dip direction.

In the other part of the model, where the extension is very small, the faults have not yet appeared. The channel is opened out like a spiral spring.

\subsubsection{Model 2: Multi-Directional Extension, Channel at the Top}

Faults are numerous and rapidly appeared. They are mainly distributed on the arms of the channel. The trend of the faults is parallel to the dip and perpendicular to the axes of the channel. Therefore, it seems that these faults are not influenced by the dip.
Model 2

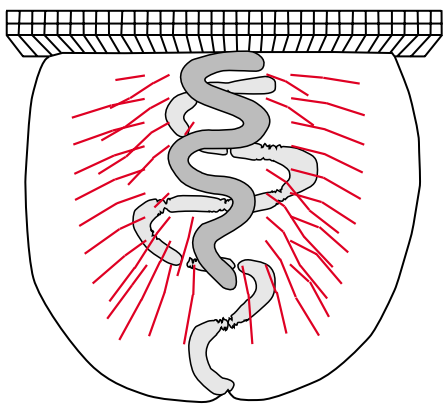

b

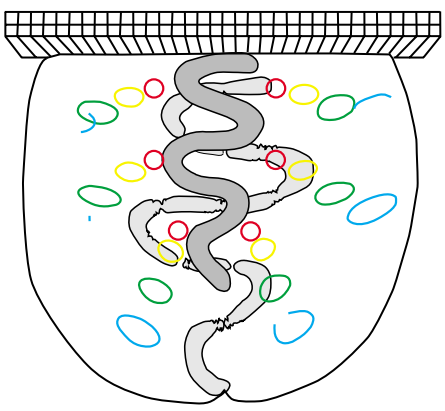

Model 3
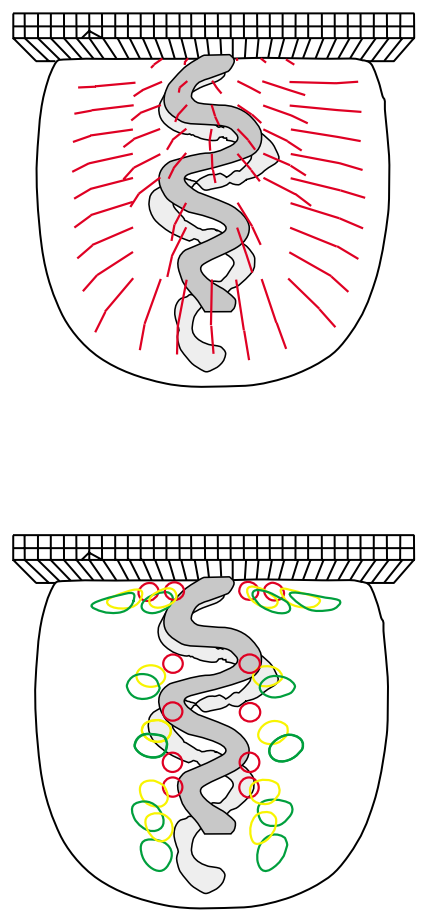

Figure 5

Drawings of Models 2 and 3. In black: the initial shape of the channel, in white: the final shape.

(a) Strain and flow lines. The initial circles (red) become ellipsoid during the experiments.

(b) Flow lines of the silicone. 


\subsubsection{Model 3: Multi-Directional Extension, Channel Buried}

Faults are less numerous than in Model 2. Extension is accommodated by the formation of "boudin" structures. Faults and boudins are essentially localised on the arms of the channel, few are in the meanders.

In this case, all conditions are met to produce a boudinage structure. This term, introduced by [7], refers to the shape that the competent layers acquire when they are sandwiched between two layers of incompetent rocks. The boudinage structure is the result of the differences in competency between the different layers. The fact that the strain is not homogeneous in layered viscous systems and that the stresses refract from layer to layer has been already highlighted [8] based on a mathematical approach. We obtain, with these analogical models, similar results when the heterogeneities are due to lateral facies variations. In both cases the results emphasise the fact that local stress direction measurements cannot be extrapolated to the regional stress field main direction.

At the sand/silicone putty interface, there are shearing forces [9]. The viscous flow (plastic flowage) of the incompetent layer creates tensile stresses in the competent layer. The channel breaks under these stresses and the fragments tend to separate.
The existence of the shearing forces is the cause of the distortion of the grid in Model 1, especially near the wedge/silicone and silicone/sand contacts.

\subsection{Characteristic Lengths of the Channels}

The comparison between Models 2 and 3 also shows the existence of shearing forces. In fact, the increase of the length of the channel at the top (Model 2) is greater than for the buried channel (Model 3) after the same deformation time.

In the case of multi-directional extension, different characteristic channel lengths, at the top and buried, have been compared: width $(a, b, c, d)$ and length $(e, f, g)$ between two meanders, length between the two extremities of the channels $(h)$.

In Figures $6 a$ and $6 b$, extension and shortening values are percentages.

\subsubsection{Model 2}

The graph indicates an increase in all lengths (between 20\% and $75 \%$ ). In the direction perpendicular to the dip (lateral extension), extension is significant in the internal part of the model and decreases toward the front: $a$ and $b>c>d$. In the direction parallel to the dip, the rate of extension increases toward the front of the model: $e$ and $f>g>h$.
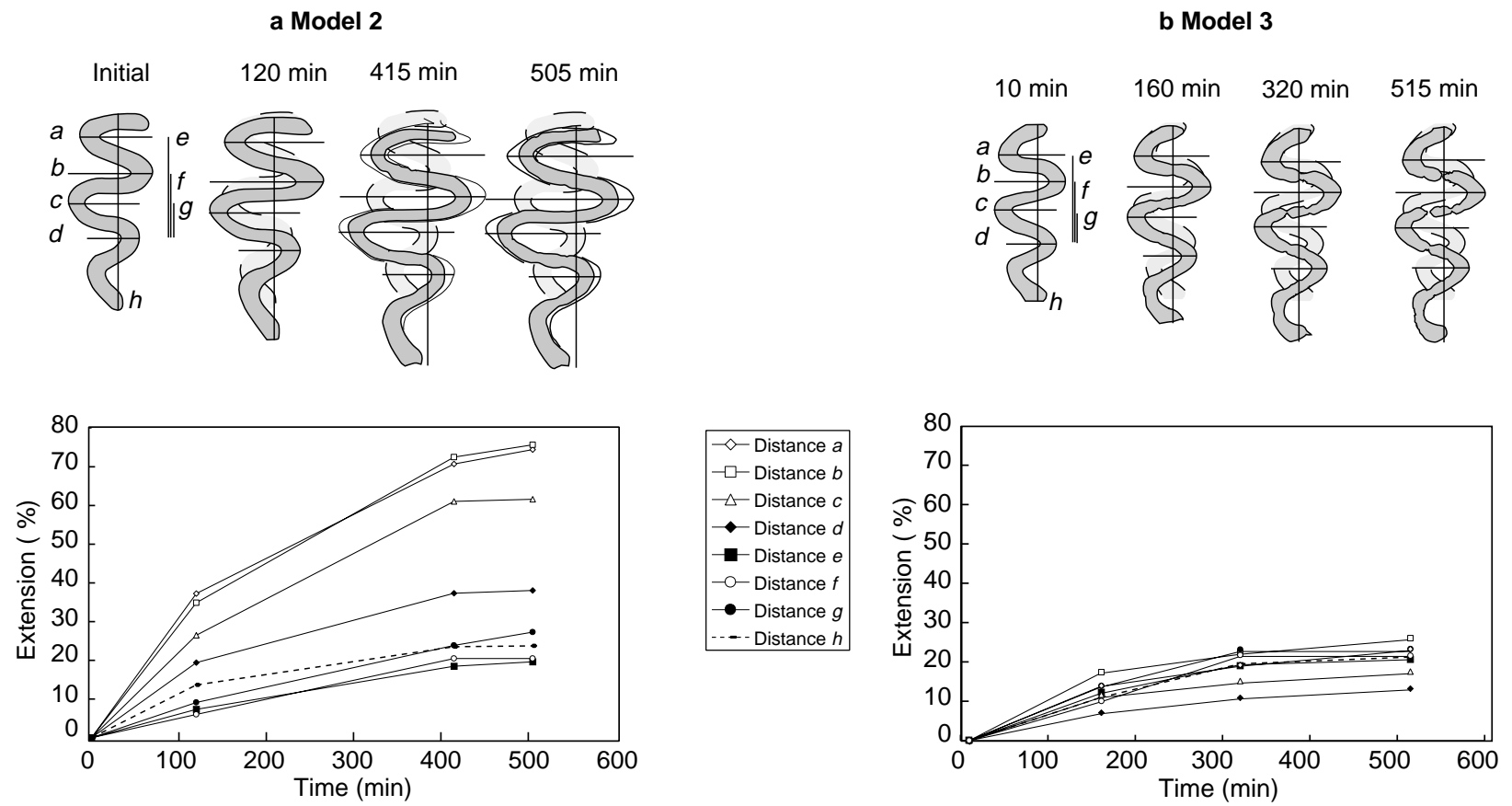

Figure 6

Extension of different characteristic lengths versus time.

(a) Model 2: channel at the top.

(b) Model 3: channel buried in the ductile layers.

We observe an increase in all lengths for Model 2, between $20 \%$ and $75 \%$, whereas for Model 3 , the rate of extension is smaller, between $15 \%$ and $25 \%$. 
Lateral extension in the internal part is progressively transformed into an extension parallel to the dip.

\subsubsection{Model 3}

The rate of extension is smaller than in Model 2 and it is more or less equivalent for all the lengths (between 15\% and $25 \%)$. However, we noticed a gentle decrease of the lateral extension towards the front of the model, as for the previous model $(a$ and $b>c>d)$.

The channel grew larger and acquired boudin structures because of the extension. The growth of this channel is homogeneous in all directions.

Deformation is localised in the boudin necks for Channel 3, whereas, in Model 2, it is more widespread: extension is accommodated by many faults. In Model 2, the channel has a passive behaviour: it undergoes the deformation of the silicone, whereas for Model 3, the channel is active. It acts as an armature that prevents the silicone from flowing.

\section{CONCLUSIONS}

In the major part of the geological environments, the decollement levels, where the shear is large due to ductile flow, are restricted and often thin. Therefore, the geometrical evolution of the area may be approached by studying the evolution of the brittle beds (see for instance [10] for the restoration of salt sheets in the Gulf of Mexico). In the Congo and Zaire deltas, the relative thicknesses of the brittle and ductile beds are inverse. There are more low competent layers than brittle sand bodies. The resulting deformation mode is difficult to quantify since it requires mass balance at a regional scale, and therefore a 3D data set. Based on the large data base acquired by the petroleum companies in such a context $[2,3]$, a model has been proposed for the multidirectional extension which takes place in such an environment [11].

In this paper, we focused on how the extension induced by gravitational gliding in the shale is accommodated by normal faulting and boudinage in sandy structures. An important point is that these faults are always perpendicular to the channel axes and are not influenced by the dip. It means that they could be invisible on the seismic data if only $2 \mathrm{D}$ data are available. Since these faults only affect the brittle sand and the shale only flows, these faults could be below the seismic resolution and therefore can be overlooked during the interpretation. Nevertheless, such a boudinage of the channels may divide the reservoir into compartments, possibly independent from a fluid flow point of view. In these models, meanders have a better continuity but more experiments with various angles between the channel position and the dips are necessary to conclude on this point.

\section{REFERENCES}

1 Bramy, T.R., Pirmiez, C., Archie, C., Heeralal, S. and Holman, K. (2000) Late Pleistocene, Deepwater Stratigraphy and Depositional Process, Offshore Trinidad \& Tobago. SPE Conf., July 10-13, Trinidad, Paper SG06.

2 Calassou, S., Rives, T., Rouby, D., Benedicto, A., Legrand, X., Janodet, D., Flament, J.M. and Lecanu, H. (1998) New Regard on 3D Extensional Deformation, 3D Structural Restoration. AAPG, Rio, Abstract.

3 Calassou, S., Claude, D., Gerard, J. and Legrand, P. (2000) Control of Deformation on Turbidite Deposit in an Extensional Domain. Lower Congo Basin-West Africa. $A A P G$, New Orleans, Abstract.

4 Trudgill, B., Rowan, M., Fiduk, J., Weimer, P., Gale, P., Korn, B., Phair, R., Gafford, W., Roberts, G. and Dobbs, S. (1999) The Perdidio Fold Belt, Northwestern Deep Gulf of Mexico, Part 1: Structural Geometry, Evolution and Regional Implications. AAPG Bulletin, 83, 1, 88-113.

5 Colletta, B., Letouzey, J., Pinedo, R., Ballard, J.F. and Balé, P. (1991) Computerised X Ray Tomography Analysis of Sandbox Models: Examples of Thin-Skinned Thrust Systems. Geology, 19, 1063-1067.

6 Cobbold, P., Rossello, E. and Vendeville, B. (1989) Some Experiments on Interacting Sedimentation and Deformation Above Salt Horizons. Bull. Soc. Géol. France, 3, 453-460.

7 Lohest, M. (1909) De l'origine des veines et des géodes des terrains primaires de Belgique, Soc. Géol. Belgique Annales, 36B, 275-282.

8 Treagus, S. (1981) A Theory of Stress and Strain Variations in Viscous Layers, and its Geological Implications. Tectonophysics, 72, 75-103.

9 Ramberg, H. (1955) Natural and Experimental Boudinage and Pinch-and-Swell Structures. Journal of Geology, 63, 512-526.

10 Moretti, I, Wu, S. and Bally, B. (1990) Computerized Balanced Cross Section (LOCACE) to Reconstruct Allochtonous Salt Sheets (Offshore Louisiana). Marine and Petroleum Geology, 7, 371-378.

11 Calassou, S. and Moretti, I. (2001) Sedimentary Flattening and Multiextensional Deformation in the West African Margin. Spec. Publication of the London Geological Society (in press).

Final manuscript received in May 2001 